ScIDice

\section{Assessment Of Apical Transportation and Volume Increase After Glide Path Using Three Different Canal Preparation Systems In-Vitro Study}

Review Article

Raghad Alhalabi ${ }^{1}$, Mohammad Salem Rekab ${ }^{2}$, Khaldaon Hossein Alhroob ${ }^{3}$, Muaaz Alkhouli ${ }^{*}$

${ }^{1}$ Department of Operative Dentistry, Faculty of Dentistry, Damascus University, Syria.

${ }^{2}$ Professor at of Operative Dentistry, Faculty of Dentistry, Damascus University, Syria.

${ }^{3}$ Department of Periodontology, Faculty of Dentistry, Damascus University, Syria.

${ }^{4}$ Department of Pediatric Dentistry, Faculty of Dentistry, Damascus University, Syria.

\title{
Abstract
}

Introduction: The preparation of root canals is one of the most critical steps of endodontic treatment; anatomical curves in root canals usually consider a confront for the medical practitioner, making a glide path in endodontic treatment became a basic principle to obtain as safe preparation.

Objectives: The research aims to assess the effectiveness of the R-Pilot system in creating the glide path with in the simulated S-shaped canal.

Material and Methods: A laboratory study to assess the efficiency of three single-file preparation system in preparing 60 transparent resin S-shaped artificial canal, the following preparation systems were used: One Curve, Hyflex EDM, XP Endo Shaper, and manual K-Files and R-Pilot mechanical patency system.

Results: No significant difference between the three preparation systems was found in terms of Apical Transportation incidence $(\mathrm{P}>0.05)$. Also, there was no difference between the two glide path creation systems used $(\mathrm{P}>0.05)$. Evaluating The amount of the removed resin using the two Glide Path systems found a significant difference at all bends between the two groups $(\mathrm{P}<0.05)$.

Conclusions: There was no difference in Apical Transportation with in all three-preparation systems. The volumetric changes in the removed resin amount have increased when using the R-Pilot system to create the glide path in the middle and the coronal area compared to a manual file.

Keywords: Endodontic; R-Pilot; Zipping; Apical Transportation.

\section{Introduction}

The essential purpose of endodontic treatment is to reduce or decrease as much as possible the microbial existence in the root canal with maintaining the normal form and route of the canal [1]. Preparing the root canals is usually considered one of the most significant steps in the endodontic treatment procedure, involving the elimination of affected and infected tissues in the root canal system to get slick walls that ease the filling and irrigation procedures, with the confirmation on preparing preservative as possible, as to secure the teeth structure from any refraction risk in the long term [2].

Anatomical bends in root canals consider a challenge on to the medical practitioner because of the possibility of complication occurrences like apparatus refraction and deviation incidence [3].

Stainless steel files can encore their standard form when preparing these bends in the opposite of nickel-titanium files which have great elasticity, allowing it to decrease the efforts and lateral forces on the canal walls in extreme bending canals as much as possible [3].

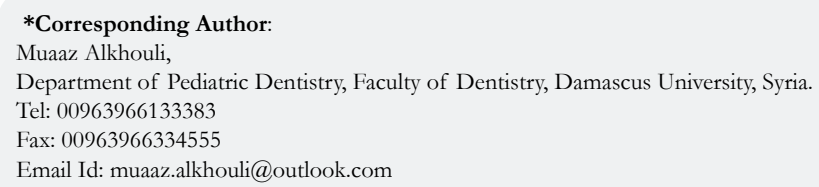

Citation: Raghad Alhalabi, Mohammad Salem Rekab, Khaldaon Hossein Alhroob, Muaaz Alkhouli. Assessment Of Apical Transportation and Volume Increase After Glide Path Using Three Different Canal Preparation Systems In-Vitro Study. Int J Dentistry Oral Sci. 2021;08(03):1811-1817. doi: http://dx.doi.org/10.19070/2377-8075-21000359

Copyright: Muaaz Alkhouli ${ }^{\circ} 2021$. This is an open-access article distributed under the terms of the Creative Commons Attribution License, which permits unrestricted use, distribution and reproduction in any medium, provided the original author and source are credited. 
The enrollment of nickel-titanium mixture in endodontic permit manufacturers to manufacture many flexible and resistant tools.

Now a days, nickel-titanium files with their diversity in forms, tapering, cross-sections, are an essential part of the everyday use by endodontic and general practitioners, those files are able to correspond with many cases due to a lot of development and features that occur on the original alloy [4].

The use of nickel titanium files, with their diverse taper and great elasticity has given the practitioner such a great ability to preserve the original bend of the root canal [5], particularly if the preparation preceded by glide path creation using the nickel-titanium files-glide path creation $[6,7]$. And that is due to the susceptibility of handling bend canals and the numerous complications that meet the practitioner when trying to prepare such canals, as canal path shift, working length loss, perforations, obturations, tools refraction, ledge consistence and zipping incidence because of the difficulty of attaining the whole working length [8], and the accompanying difficulties in performing the residual therapeutic procedures [9].

Wither the glide path had been created by a mechanical or by manual files, creating the glide path in endodontic treatment has become a recommended essential principle to secure a very safe preparation [10].

Creating a glide path is usually defined as a smooth-walled path start from the canal aperture and end with physiological apical Forman.

This is accomplished when the file in which the glide path had been created gets in the whole canal length easily without any resistance [11], which will ease the preparation procedure because it give the practitioner a path the lets bigger files to smoothly enter the canal [12].

So, the purpose of this research was to evaluate the glide path creation using mechanical files in preserving the original form and centric of the root canal during the canal preparation in one of the most sophisticated cases in endodontic therapy, the S-shaped canals using a three-single mechanical preparation system.

\section{Objectives:}

Evaluate the effectiveness of the R-Pilot system in creating the glide path with in the Simulated S-Shaped canals in Apical Transportation and Volume Increase, in addition to evaluate and compare the changes in the original anatomical shape of these simulated canals when using the single-filed mechanical root canal preparation systems in rotational motion (One Curve, XP Endo Shaper, Hyflex EDM) After securing patency using the R-Pilot system and manual files.

\section{Material and Methods}

\section{Study Design:}

This study was designed as an in-vitro study to evaluate the efficacy of preparing synthetic transparent resin S-shaped canals using three single-file preparation systems, after securing a manual or mechanical patency, and studying the accompanying complications and changes that happen when preparing this kind of canals to define the best-used preparation system and the best patency technique.

\section{Study Sample:}

The study sample consisted of 60 S-shaped canals (Endo Training Bloc S-Shape, DENTSPLY Sirona , Ballaignes, Switzerland) made of transparent resin with the diameter and taper corresponding to the ISO measurement, where the apex measurement was 0.15 , a taper of $2 \%$, and a working length of $16 \mathrm{~mm}$ for each canal, with two coronal and apical curvature.

The sample was divided randomly into two groups (A and B), referring to the used patency technique, manually and mechanically, respectively. Each of them includes 30 canals $(n=30)$. Then each group was divided into three subgroups and named after the type of the used preparation system $(\mathrm{O}, \mathrm{X}, \mathrm{H}), 10$ canals for each. The blocks were numbered from 1 to 10 in each group.

The study groups were divided according to the following:

Xa Group: 10 canals, XP Endo shaper preparation, and patency with manual files.

Xb Group: 10 canals, XP Endo shaper preparation, patency with R-Pilot mechanical file.

Ha Group: 10 canals, preparation with Hyflex EDM system, patency with manual files.

Hb Group: 10 canals, Preparation with Hyflex EDM, patency with R-Pilot mechanical file.

Oa Group: 10 canals, One Curve preparation system, patency with manual files.

Ob Group: 10 canals, One Curve preparation system, patency with R-Pilot mechanical file.

\section{Study Procedure:}

The simulated canals were all prepared by the same endodontist using instruments up to the working length, which was set on the canal exit of the resin canal blocks. A glide path was established with K-files till the size 20\# in A Groups and using R-Pilot mechanical file in B Groups to the working length, and then all canals were prepared according to the companies instructions using torque-controlled endodontic motor (Silver Reciproc; VDW, Munich, German).

The S-shaped canal within the resin blocks had been fixed in a base particularly designed for this research, solar images had been possessed using a digital camera under unified conditions in terms of angle, dimension and illumination and the images had been superimposed by using Adobe Photoshop software.

The amounts of removed resin from the walls were determined from inner and outer curvature sides on levels determined perpendicular to the longitudinal axis of the canal (figure 1). Those 
Figure 1 . The study sections.

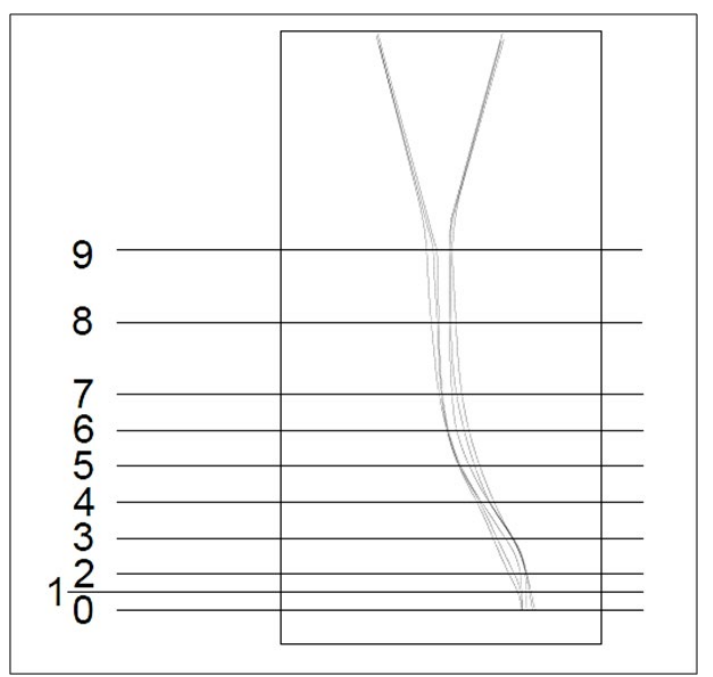

points were set depending on the primary image. Then, every canal had been sectioned to three areas the apical curvature area (section $0,1,2,3$ ), the first curvature (section 4,5,6,7) and the coronal area (section 8,9).

After determining these areas and levels, we can examine the changes along the canal length, based on the following criteria to evaluate the difference in the original shape of the canal in terms of the following:

The removed resin amount: The sum of the removed amount from both right and left sides.

Apical Transportation.

Following collection, the data was entered and analyzed using the Statistical Package for the Social Sciences Version 13.0 (SPSS, Inc, Chicago, USA). Statistical analysis was conducted with the significance level of $0.05(\mathrm{P}<0.05)$. ANOVA test was used to determine the existence of significant statistical differences when more than two independent variables were compared, and the Bonferroni correction was used to perform multiple comparisons.

\section{Results}

The research sample consisted of 600 different sections determined in 60 simulated S-shaped root canals. The sample was divided in to two groups according to the glide path creation technique (R-Pilot, and manual files), and each group was divided into three subgroups (One Curve preparation system, XP Endo Shaper preparation system, Hyflex EDM preparation system). In addition, 10 different sections were made in each simulated canal; the sections were divided according to the studied area to the apical curvature area; the first curvature area, and the straight coronal area.

\section{Studying The Apical Transportation Occurrence:}

Table No 1 shows the Apical Transportation occurrence number according to each one of the studied groups.

A chi-square test was also performed to study the differences in the frequencies of the Apical Transportation occurrences between the glide path creation group using the R-Pilot system and the glide path creation group using manual files in the research sample. Also, according to the preparation system used, as follows:

There were no statistically significant differences in the frequencies of the Apical Transportation occurrences between the glide path creation group using the R-Pilot system and the glide path creation group using manual files regardless of the preparation system used in the research sample, as the significance level value was greater than $(\mathrm{p}>0.05)$ in All groups.

A chi-square test was also performed to study the existence of a significant difference in the Apical Transportation occurrence for each of the preparation systems. Table No. 2 shows the result of this test, as there was no significant difference within the groups of the preparation system.

\section{Studying The Resin Removed Amount:}

Table No. 2 shows the mean of the removed resin amount, according to each followed method and to the studied area in the simulated canal, the highest removed resin value was in the coronal area which used the R-Pilot system $(4.2 \mathrm{~mm})$, and a T Student test was performed for independent samples to study the differences significance in the removed resin values mean after creating the glide path (in $\mathrm{mm}$ ) between the glide path creation group using R-Pilot system and the glide path creation group which used manual files in the research sample, where a significant difference was found between the two systems used for all the studied areas, and also for the entire canal value, where the significance level in all groups was less than (0.05).

Figure 2 shows the removed resin amount according to the used preparation system, where the removed amount in the R-Pilot system was significantly greater in both straight coronal area (4.2 $\mathrm{mm})$ and first curvature area $(1.99 \mathrm{~mm})$, while it was significantly lower at the apical curvature area using the R-Pilot system (1.49 $\mathrm{mm})$.

ANOVA test was also performed to study the effect of the used 
Table 1. Apical Transportation occurrence number according to the studied groups-chi-square test.

\begin{tabular}{|c|c|c|c|c|c|c|c|}
\hline \multirow{2}{*}{\multicolumn{2}{|c|}{ Methods }} & \multicolumn{6}{|c|}{ Number of stimulated canals } \\
\hline & & \multirow{2}{*}{$\begin{array}{c}\begin{array}{c}\text { No Apical } \\
\text { Transportation }\end{array} \\
9 \\
\end{array}$} & \multirow{2}{*}{$\begin{array}{c}\begin{array}{c}\text { Apical } \\
\text { Transportation }\end{array} \\
1 \\
\end{array}$} & \multirow{2}{*}{$\begin{array}{c}\text { Total } \\
10 \\
\end{array}$} & \multirow{3}{*}{$\begin{array}{c}\begin{array}{c}\text { Chi } \\
\text { square }\end{array} \\
1.25\end{array}$} & \multirow{3}{*}{$\frac{P \text {-value }}{0.264}$} & \multirow{3}{*}{$\begin{array}{c}\begin{array}{c}\text { signifi- } \\
\text { cance }\end{array} \\
\text { NS }\end{array}$} \\
\hline \multirow{2}{*}{ One Curve } & R-Pilot & & & & & & \\
\hline & Hand files & 7 & 3 & 10 & & & \\
\hline \multirow{2}{*}{ XP Endo Shaper } & R-Pilot & 10 & 0 & 10 & \multirow{2}{*}{2.22} & \multirow{2}{*}{0.136} & \multirow{2}{*}{ NS } \\
\hline & Hand files & 8 & 2 & 10 & & & \\
\hline \multirow{2}{*}{ Hyflex EDM } & R-Pilot & 8 & 2 & 10 & \multirow{2}{*}{0} & \multirow{2}{*}{1} & \multirow{2}{*}{ NS } \\
\hline & Hand files & 8 & 2 & 10 & & & \\
\hline \multicolumn{8}{|c|}{ Chi square test between the two methods } \\
\hline \multicolumn{2}{|c|}{ Method } & \multicolumn{2}{|c|}{ Number of stimulated canals } & \multicolumn{2}{|c|}{ Chi square } & P-value & $\begin{array}{l}\text { sig- } \\
\text { nifica } \\
\text { nce }\end{array}$ \\
\hline \multicolumn{2}{|c|}{ R-Pilot } & \multicolumn{2}{|c|}{30} & \multicolumn{2}{|c|}{2.222} & 0.329 & NS \\
\hline \multicolumn{2}{|c|}{ Hand files } & \multicolumn{2}{|c|}{30} & \multicolumn{2}{|c|}{0.373} & 0.83 & NS \\
\hline
\end{tabular}

Table 2. The mean of the removed resin amount - $T$ student test.

\begin{tabular}{|c|c|c|c|c|c|c|c|}
\hline \multicolumn{2}{|c|}{ Method } & number & SD & SE & T-value & $P$-value & Significance \\
\hline \multirow{2}{*}{$\begin{array}{c}\text { Apical } \\
\text { curvature }\end{array}$} & R-Pilot & 120 & 1.49 & 0.55 & \multirow{2}{*}{-2.298} & \multirow{2}{*}{0.022} & \multirow{2}{*}{$\mathrm{s}$} \\
\hline & Hand files & 120 & 1.66 & 0.6 & & & \\
\hline \multirow{2}{*}{$\begin{array}{c}\text { First } \\
\text { curvature }\end{array}$} & R-Pilot & 120 & 1.99 & 0.42 & \multirow{2}{*}{8.72} & \multirow{2}{*}{0} & \multirow{2}{*}{$\mathrm{s}$} \\
\hline & Hand files & 120 & 1.45 & 0.53 & & & \\
\hline \multirow{2}{*}{$\begin{array}{c}\text { Coronal } \\
\text { area }\end{array}$} & R-Pilot & 60 & 4.2 & 1.39 & \multirow{2}{*}{13.334} & \multirow{2}{*}{0} & \multirow{2}{*}{$\mathrm{s}$} \\
\hline & Hand files & 60 & 1.56 & 0.65 & & & \\
\hline \multirow{2}{*}{$\begin{array}{l}\text { Full } \\
\text { canal }\end{array}$} & R-Pilot & 300 & 2.23 & 1.26 & \multirow{2}{*}{8.393} & \multirow{2}{*}{0} & \multirow{2}{*}{$\mathrm{s}$} \\
\hline & Hand files & 300 & 1.55 & 0.59 & & & \\
\hline
\end{tabular}

preparation system in the amount of the removed resin quantity after preparation according to the studied area and the followed way in glide path creation.

Table No. 3 shows the results of this test, we note that there is a significantly important differences, in all studied areas, the removed resin amount after preparation was larger when using the R-pilot system, where as, when using manual files, significantly important differences were found only in the first curvature area (0.000), straight coronal area (0.000) and the entire canal (0.001) as the removed resin amount was greater after preparation.

Table No. 4 shows the results of the Bonferroni test for comparing the removed resin amount variable after preparation between the two different preparation systems considering the difference in the studied area and the glide path creation technique.

\section{Discussion}

The mechanical preparation of root canal system importance comes from the elimination of live and dead tissue and the production of adequate space that permit irrigation fluids, filling materials, and intra-canalicular dressing to easily enter the canal to accomplish their role in seal and disinfect the root canal system [13], with maintaining the canal original form [14].
As the canals anatomical abnormalities and bends are considered a serious challenges that may face the medical practitioner during the endodontic therapy because of the multiple possible complications that may occur during treatment like canal deviation, zipping incidence, apex opening or changing in the form or the location, which may cause a following failure of the endodontic therapy [15].

In spite of the advantages and the huge elasticity of nickel-titanium mechanical files. Creating a glide path-manually or mechanically-still consider one of the recommended steps that should be taken prior to the use of mechanical preparation tools [16].

In this study, instead of using natural teeth, S-shaped resin blocks had been used because of the inefficacy of the natural teeth for preparation system comparison, where even minor differences between those teeth are able to make a clear variance in the results more than any preparation system can be made[17], so it give the resin blocks the ability to unified the required criteria in the study sample, in terms of stiffness, length, bend radius and angle, manufacture's substance[18, 19]. So, although the resin blocks might not reflect all the clinical features because of the differentiation between the stiffness of the resin and the dentin [20], but still a good and valid measure to study diverse preparation systems [21, 22]. 
Table 3. The amount of resin removed (ANOVA test).

\begin{tabular}{|c|c|c|c|c|c|c|c|c|c|c|}
\hline \multicolumn{3}{|c|}{ Method } & $\mathbf{N}$ & mean & SD & Min & Max & F-value & P-value & Sig \\
\hline \multirow{12}{*}{ R-Pilot } & \multirow{3}{*}{$\begin{array}{c}\text { Apical } \\
\text { curvature }\end{array}$} & One Curve & 40 & 3.04 & 1.05 & 1.44 & 6.17 & \multirow{3}{*}{9.145} & \multirow{3}{*}{0} & \multirow{3}{*}{$S$} \\
\hline & & XP Endo Shaper & 40 & 3.05 & 0.65 & 1.98 & 4.69 & & & \\
\hline & & Hyflex EDM & 37 & 3.94 & 1.38 & 1.37 & 7.65 & & & \\
\hline & \multirow{3}{*}{$\begin{array}{c}\text { First } \\
\text { curvature }\end{array}$} & One Curve & 40 & 3.76 & 0.77 & 2.27 & 5.05 & \multirow{3}{*}{12.874} & \multirow{3}{*}{0} & \multirow{3}{*}{$S$} \\
\hline & & XP Endo Shaper & 40 & 3.51 & 0.67 & 1.8 & 5.03 & & & \\
\hline & & Hyflex EDM & 40 & 4.3 & 0.69 & 2.44 & 5.22 & & & \\
\hline & \multirow{3}{*}{$\begin{array}{l}\text { Coronal } \\
\text { curvature }\end{array}$} & One Curve & 20 & 6.35 & 0.85 & 4.92 & 7.68 & \multirow{3}{*}{5.82} & \multirow{3}{*}{0.005} & \multirow{3}{*}{ S } \\
\hline & & XP Endo Shaper & 20 & 5.42 & 1.01 & 3.18 & 7.37 & & & \\
\hline & & Hyflex EDM & 20 & 6.1 & 0.81 & 4.49 & 7.61 & & & \\
\hline & \multirow{3}{*}{ Full canal } & One Curve & 100 & 3.99 & 1.52 & 1.44 & 7.68 & \multirow{3}{*}{9.8} & \multirow{3}{*}{0} & \multirow{3}{*}{$\mathrm{S}$} \\
\hline & & XP Endo Shaper & 100 & 3.71 & 1.15 & 1.8 & 7.37 & & & \\
\hline & & Hyflex EDM & 97 & 4.54 & 1.31 & 1.37 & 7.65 & & & \\
\hline \multirow{12}{*}{ Hand files } & \multirow{3}{*}{$\begin{array}{c}\text { Apical } \\
\text { curvature }\end{array}$} & One Curve & 40 & 3.01 & 1.24 & 1.06 & 6.38 & \multirow{3}{*}{2.62} & \multirow{3}{*}{0.077} & \multirow{3}{*}{ NS } \\
\hline & & XP Endo Shaper & 40 & 3.55 & 0.88 & 1.99 & 5.53 & & & \\
\hline & & Hyflex EDM & 40 & 3.42 & 1.13 & 1.79 & 6.4 & & & \\
\hline & \multirow{3}{*}{$\begin{array}{l}\text { First curva- } \\
\text { ture }\end{array}$} & One Curve & 40 & 3.67 & 0.72 & 2.2 & 5.24 & \multirow{3}{*}{23.625} & \multirow{3}{*}{0} & \multirow{3}{*}{ S } \\
\hline & & XP Endo Shaper & 40 & 3.48 & 0.53 & 1.74 & 4.5 & & & \\
\hline & & Hyflex EDM & 40 & 4.36 & 0.54 & 2.75 & 5.07 & & & \\
\hline & \multirow{3}{*}{$\begin{array}{l}\text { Coronal } \\
\text { curvature }\end{array}$} & One Curve & 20 & 5.92 & 0.93 & 3.95 & 7.22 & \multirow{3}{*}{27.748} & \multirow{3}{*}{0} & \multirow{3}{*}{$\mathrm{S}$} \\
\hline & & XP Endo Shaper & 20 & 4.21 & 0.57 & 3.21 & 5.7 & & & \\
\hline & & Hyflex EDM & 20 & 5.89 & 0.93 & 3.04 & 7.01 & & & \\
\hline & & One Curve & 100 & 3.86 & 1.46 & 1.06 & 7.22 & & & \\
\hline & Full canal & XP Endo Shaper & 100 & 3.65 & 0.75 & 1.74 & 5.7 & 7.375 & 0.001 & S \\
\hline & & Hyflex EDM & 100 & 4.29 & 1.27 & 1.79 & 7.01 & & & \\
\hline
\end{tabular}

The results of our study showed that when comparing the two methods of creating a glide path 'with an R-Pilot mechanical file and using manual K-Files up to the size of \# 20' the amount of removed resin in the apical curvature area In the group which used manual files, increased compared to the group using mechanical files, and the increase in the removed resin amount in the first curvature area and in the straight area in the group using a mechanical file to create the glide path comparing to the glide path creation group using manual files, can be explained by the difference in the size and taper of the files, Where the size of the mechanical file apic is 12.5 \# With a $4 \%$ taper compared to the manual K-file size \# 20 and a $\%$ taper.

As for the amount of removed resin after preparation using different single-filed preparation systems, This study showed that the amount of removed resin using the Hyflex EDM preparation system was greater than what it is in both preparation groups the One Curve system and the XP Endo Shaper system in the different studied areas, and with the different system used to create the glide path, followed by the preparation group with the One Curve system, then the preparation group using the XP Endo Shaper system, and this can be explained by the difference in the taper of applied preparation systems, as the Hyflex One File preparation file has an endless taper from its apic to the end of its working length, where as, the One Curve file, had a fixed taper of $6 \%$, and the XP Endo Shaper file had a taper of 1\%, but reached a prepa- ration of $4 \%$ due to the rolling motion of the file.

Our study agreed with(Htun PH 2020)[23], who compared between creation of glide path using manual files and mechanical files in curved canals, where both studies showed that the mechanical files used in the process of creating the glide path caused a greater volumetric changes compared with manual files.

Also, when compared with a previous study [13] which assess the ability of four preparation systems in forming 80 curved mesial canals using each of (Hyflex EDM - Wave One Gold - One Shape - Reciproc Blue) in which the Hyflex EDM preparation system ranked first in terms of volumetric changes in the used canals; The variable cross-section along the length of the file, as well as the endless taper and the alloy that subjected to electrical displacement, could be an important cause of the volumetric changes that occur as a result of its increased cutting efficiency.

When compared with (Ozyurek $\mathrm{T}$ et al. 2015), which compared Hyflex EDM with both Reciproc and Wave one Gold, the results of our study differed with this study, which showed that the Hyflex group caused the least amount of volumetric changes after preparation, the reason of the difference may be due to the variance in the used files in the two studies. Hyflex file had the smallest taper compared to the other files used in this study, while it had the largest taper compared to the other preparation systems used in our study [24]. 
Table 4. Bonferroni test for comparing the removed resin amount variable.

\begin{tabular}{|c|c|c|c|c|c|c|c|}
\hline \multicolumn{2}{|c|}{ Method } & $\begin{array}{l}\text { Preparation } \\
\text { method (I) }\end{array}$ & $\begin{array}{l}\text { Preparation } \\
\text { method }(J)\end{array}$ & $(\mathrm{I}-\mathrm{J})$ & SE & P-value & Sig \\
\hline \multirow{12}{*}{ R-Pilot } & \multirow{3}{*}{$\begin{array}{c}\text { Apical } \\
\text { curvature }\end{array}$} & \multirow{2}{*}{ One Curve } & XP Endo Shaper & -0.01 & 0.24 & 1 & NS \\
\hline & & & Hyflex EDM & -0.91 & 0.24 & 0.001 & S \\
\hline & & XP Endo Shaper & Hyflex EDM & -0.89 & 0.24 & 0.001 & $S$ \\
\hline & \multirow{3}{*}{$\begin{array}{c}\text { First } \\
\text { curvature }\end{array}$} & \multirow{2}{*}{ One Curve } & XP Endo Shaper & 0.26 & 0.16 & 0.333 & NS \\
\hline & & & Hyflex EDM & -0.54 & 0.16 & 0.003 & $\mathrm{~S}$ \\
\hline & & XP Endo Shaper & Hyflex EDM & -0.79 & 0.16 & 0 & S \\
\hline & \multirow{3}{*}{$\begin{array}{l}\text { Coronal } \\
\text { curvature }\end{array}$} & \multirow{2}{*}{ One Curve } & XP Endo Shaper & 0.93 & 0.28 & 0.005 & $\mathrm{~S}$ \\
\hline & & & Hyflex EDM & 0.25 & 0.28 & 1 & NS \\
\hline & & XP Endo Shaper & Hyflex EDM & -0.69 & 0.28 & 0.056 & NS \\
\hline & \multirow{3}{*}{ Full canal } & \multirow{2}{*}{ One Curve } & XP Endo Shaper & 0.28 & 0.19 & 0.4 & NS \\
\hline & & & Hyflex EDM & -0.55 & 0.19 & 0.013 & $S$ \\
\hline & & XP Endo Shaper & Hyflex EDM & -0.83 & 0.19 & 0 & $S$ \\
\hline \multirow{9}{*}{ Hand files } & \multirow{3}{*}{$\begin{array}{c}\text { First } \\
\text { curvature }\end{array}$} & \multirow{2}{*}{ One Curve } & XP Endo Shaper & 0.19 & 0.13 & 0.454 & NS \\
\hline & & & Hyflex EDM & -0.69 & 0.13 & 0 & $S$ \\
\hline & & XP Endo Shaper & Hyflex EDM & -0.88 & 0.13 & 0 & $S$ \\
\hline & \multirow{3}{*}{$\begin{array}{l}\text { Coronal curva- } \\
\text { ture }\end{array}$} & \multirow{2}{*}{ One Curve } & XP Endo Shaper & 1.71 & 0.26 & 0 & $\mathrm{~S}$ \\
\hline & & & Hyflex EDM & 0.03 & 0.26 & 1 & NS \\
\hline & & XP Endo Shaper & Hyflex EDM & -1.68 & 0.26 & 0 & $\mathrm{~S}$ \\
\hline & \multirow{3}{*}{ Full canal } & \multirow{2}{*}{ One Curve } & XP Endo Shaper & 0.21 & 0.17 & 0.68 & NS \\
\hline & & & Hyflex EDM & -0.43 & 0.17 & 0.034 & $S$ \\
\hline & & XP Endo Shaper & Hyflex EDM & -0.64 & 0.17 & 0.001 & $S$ \\
\hline
\end{tabular}

Figure 2. Average amount of resin removed after glide path creation using different methods.

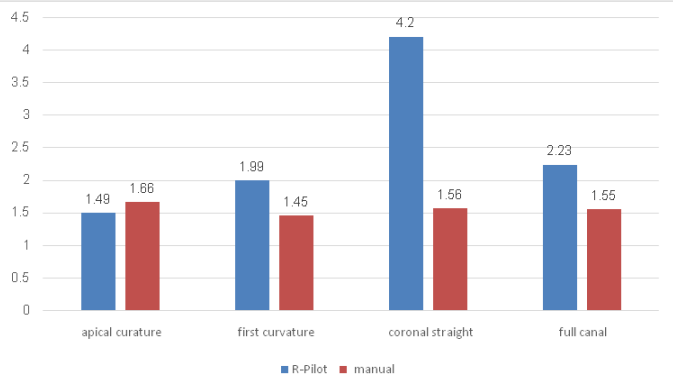

As for the occurrence of Apical Transportation, we found in this study that both methods used to create the glide path have an equal effect in terms of Apical Transportation incidence, statistically. despite the fact that the Apical Transportation cases were greater in the glide path created by using manual files compared to those created by using the R-Pilot mechanical file, this may be clinically significant separately from its statistical significance.

Our study agreed with previous study [25], which compared between the process ofcreating a glide path using manual files and two types of mechanical patency files in curved canals, and showed that there were no statistically significant differences in the probability of Apical Transportation occurrence between those different groups.
It also agreed with another study [26], which compared creating the glide path using manual files or by using both Path File and G-File systems in a sample of 45 curved canal where no specific method of the creating process affected the occurrence of Apical Transportation.

As the comparison between this study and that of [27], in which they compared glide path using manual k-files and the both the Path File and Wave One Gold Glider systems. We differed with that study; which showed that creating a Glide Path using manual files has the maximum possible canal and apical transmission.

Several factors have been identified to affect the probability of Apical Transportation occurrence such as anatomical anomalies of the root canal system, file's shape and design, file alloy and the used preparation technique [28]. 


\section{Conclusion}

The volumetric changes in the removed resin amount has increased when using the R-Pilot system to create the glide path in the middle and in the coronal area compared to the use of manual file, more over it has a similar affect due to the Apical Transportation occurrence probability. There was no difference in Apical Transportation with in all three preparation systems, while Greater volumetric changes were observed when using The Hyflex EDM preparation System compared to the Curve and XP Endo shaper system.

\section{References}

[1]. Saberi E, Farhad-Mollashahi N, Bijari S, Daryaeian M. Comparative Evaluation of Root Canal Transportation by Three NiTi Single-File Systems in Curved Canals: A Cone Beam Computed Tomography Study. Int J Dent 2018;2018.Pubmed PMID: 29861728.

[2]. Wu H, Peng C, Bai Y, Hu X, Wang L, Li C. Shaping ability of ProTaper Universal, WaveOne and ProTaper Next in simulated L-shaped and S-shaped root canals. BMC Oral Health 2015;15(1):27.Pubmed PMID: 25886847.

[3]. Coleman CL, Svec TA. Analysis of Ni-Ti versus stainless steel instrumentation in resin simulated canals. J Endod 1997;23(4):232-5.Pubmed PMID:9594772.

[4]. Özyürek T, Gündoğar M, Yılmaz K, Uslu G. Bending resistance and cyclic fatigue life of Reciproc Blue, WaveOne Gold, and Genius files in a double (S-shaped) curved canal. J Dent Res Dent Clin Dent Prospects 2017;11(4):241-6.Pubmed PMID:29354251.

[5]. Yoshimine Y, Ono M, Akamine A. The shaping effects of three nickeltitanium rotary instruments in simulated S-shaped canals. J Endod 2005;31(5):373-5.Pubmed PMID:.15851932.

[6]. Hiran-us S, Pimkhaokham S, Sawasdichai J, Ebihara A, Suda H. Shaping ability of ProTaper NEXT, ProTaper Universal and iRace files in simulated S-shaped canals. Aust Endod J 2016;42(1):32-6.Pubmed PMID:26420685.

[7]. Zanette F, Grazziotin-Soares R, Flores ME, Fontanella VRC, Gavini G, Barletta FB. Apical root canal transportation and remaining dentin thickness associated with ProTaper Universal with and without PathFile. J Endod 2014;40(5):688-93.Pubmed PMID:24767565.

[8]. Ha J-H. Safe root canal preparation using reciprocating nickel-titanium instruments. Restor Dent Endod 2015;40(3):253-4.Pubmed PMID:26295031.

[9]. Weine FS, Kelly RF, Lio PJ. The effect of preparation procedures on original canal shape and on apical foramen shape. J Endod 1975;1(8):255-62.Pubmed PMID:10697472.

[10]. Zheng L, Ji X, Li C, Zuo L, Wei X. Comparison of glide paths created with K-files, PathFiles, and the ProGlider file, and their effects on subsequent WaveOne preparation in curved canals. BMC Oral Health 2018;18(1):152. Pubmed PMID:30157822.

[11]. West J. Endodontic update 2006. J Esthet Restor Dent 2006;18(5):280300.Pubmed PMID:16987326.

[12]. Di Fiore PM. A dozen ways to prevent nickel-titanium rotary instrument fracture. J Am Dent Assoc 2007;138(2):196-201.Pubmed PMID:17272374.
[13]. Elashiry MM, Saber SE, Elashry SH. Comparison of Shaping Ability of Different Single-File Systems Using Microcomputed Tomography. Eur J Dent 2020;14(1):70-6.Pubmed PMID:32005040.

[14]. Alfadley A, Alrajhi A, Alissa H, Alzeghaibi F, Hamadah L, Alfouzan K, et al. Shaping ability of XP endo shaper file in curved root canal models. Int J Dent 2020;2020:4687045.Pubmed PMID: 32148503.

[15]. Poly A, AlMalki F, Marques F, Karabucak B. Canal transportation and centering ratio after preparation in severely curved canals: analysis by microcomputed tomography and double-digital radiography. Clin Oral Investig 2019;23(12):4255-62.Pubmed PMID:30834991.

[16]. Webber M, Piasecki L, Jussiani EI, Andrello AC, dos Reis PJ, Azim KA, et al. Higher Speed and No Glide Path: A New Protocol to Increase the Efficiency of XP Shaper in Curved Canals-An In Vitro Study. J Endod 2020;46(1):103-9.Pubmed PMID:31761330.

[17]. Peters OA, Laib A, Göhring TN, Barbakow F. Changes in root canal geometry after preparation assessed by high-resolution computed tomography. J Endod 2001;27(1):1-6.Pubmed PMID:11487156.

[18]. Huang Z, Quan J, Liu J, Zhang W, Zhang X, Hu X. A microcomputed tomography evaluation of the shaping ability of three thermally-treated nickeltitanium rotary file systems in curved canals. J Int Med Res 2019;47(1):32534.Pubmed PMID:30282507.

[19]. Pacheco-Yanes J, Gazzaneo I, Pérez AR, Armada L, Neves MA. Transportation assessment in artificial curved canals after instrumentation with Reciproc, Reciproc Blue, and XP-endo Shaper Systems. J Investig Clin Dent 2019;10(3):e12417.Pubmed PMID:30955238.

[20]. Vallaeys K, Chevalier V, Arbab-Chirani R. Comparative analysis of canal transportation and centring ability of three $\mathrm{Ni}-\mathrm{Ti}$ rotary endodontic systems: Protaper ${ }^{\circ}, \mathrm{MTwo}^{\circ}$ and Revo-S $\mathrm{S}^{\mathrm{TM}}$, assessed by micro-computed tomography. Odontology 2016;104(1):83-8.Pubmed PMID:25248755.

[21]. Saleh AM, Gilani PV, Tavanafar S, Schäfer E. Shaping ability of 4 different single-file systems in simulated S-shaped canals. J Endod 2015;41(4):54852.Pubmed PMID:25576206.

[22]. Wei Z, Cui Z, Yan P, Jiang H. A comparison of the shaping ability of three nickel-titanium rotary instruments: a micro-computed tomography study via a contrast radiopaque technique in vitro. BMC Oral Health 2017;17(1):39. Pubmed PMID:28068971.

[23]. Htun PH, Ebihara A, Maki K, Kimura S, Nishijo M, Tokita D, et al. Comparison of torque, force generation and canal shaping ability between manual and nickel-titanium glide path instruments in rotary and optimum glide path motion. Odontology 2020;108(2):188-93.Pubmed PMID:31506734.

[24]. Özyürek T, Yılmaz K, Uslu G. Shaping ability of Reciproc, WaveOne GOLD, and HyFlex EDM single-file systems in simulated S-shaped canals. J Endod 2017;43(5):805-9.Pubmed PMID:28292599.

[25]. Türker S-A, Uzunoğlu E. Apical root canal transportation of different pathfinding systems and their effects on shaping ability of ProTaper Next. J Clin Exp Dent 2015;7(3):e392-5.Pubmed PMID:26330936.

[26]. D’Amario M, Baldi M, Petricca R, De Angelis F, El Abed R, D'Arcangelo C. Evaluation of a new nickel-titanium system to create the glide path in root canal preparation of curved canals. J Endod 2013;39(12):1581-4.Pubmed PMID:24238451.

[27]. Vorster M, van der Vyver PJ, Paleker F. Canal transportation and centering ability of WaveOne Gold in combination with and without different glide path techniques. J Endod 2018;44(9):1430-5.Pubmed PMID:30078574.

[28]. Bürklein S, Poschmann T, Schäfer E. Shaping ability of different nickeltitanium systems in simulated S-shaped canals with and without glide path. J Endod 2014;40(8):1231-4.Pubmed PMID:25069939. 